\title{
PERAN KUALITAS PELAYANAN, HARGA DAN PRODUK TERHADAP KEPUASAN DAN LOYALITAS NASABAH PADA BCA INSURANCE SOLO
}

\section{THE ROLE OF SERVICE QUALITY, PRICES AND PRODUCTS ON CUSTOMER SATISFACTION AND LOYALTY IN SOLO BCA INSURANCE}

\author{
Yunita Ulvi Srihastanti ${ }^{1}$, Lilis Sulistyani ${ }^{2}$ \\ Sekolah Tinggi Ilmu Ekonomi Adi Unggul Bhirawa Surakarta \\ Email :yunitaulvisrihastanti@gmail.com
}

\begin{abstract}
ABSTRAK
Tujuan dari penelitian ini adalah untuk menguji peran kualitas pelayanan, harga dan produk terhadap kepuasan dan loyalitas nasabah pada BCA Insurance Solo.

Populasi dalam penelitian ini nasabah BCA Insurance Solo. Jumlah sampel yang digunakan sebanyak 100 responden dengan teknik purposive sampling. Teknik analisis yang digunakan adalah uji validitas dan uji reliabilitas, uji linieritas, analisis regresi, analisis jalur, Uji parsial t, Uji F, Uji koefisien determinasi dan analisis korelasi.

Hasil penelitian menunjukkan bahwa: kualitas pelayanan, harga dan produk berpengaruh positif dan signifikan terhadap kepuasan nasabah. Kualitas pelayanan, harga, produk dan kepuasan berpengaruh positif dan signifikan terhadap loyalitas nasabah. Hasil analisis jalur menunjukkan bahwa: Pengaruh langsung kualitas pelayanan terhadap loyalitas nasabah lebih efektif melalui jalur langsung. Pengaruh langsung harga terhadap loyalitas nasabah lebih efektif melalui jalur langsung pada variabel harga. Pengaruh langsung produk terhadap loyalitas nasabah lebih efektif melalui jalur langsung pada variabel produk. Hasil analisis jalur membuktikan bahwa variabel kepuasan bukan merupakan variabel mediasi. Hasil uji $\mathrm{R}^{2}$ total sebesar 0,913 dapat diartikan loyalitas nasabah BCA Insurance Solo dijelaskan oleh variabel kualitas pelayanan, harga, produk dan kepuasan nasabah sebesar $91,3 \%$.
\end{abstract}

Kata Kunci : : Kualitas Pelayanan, Harga, Produk, Kepuasan, Loyalitas Nasabah, BCA Insurance Solo

\section{ABSTRACT}

The purpose of this study is to examine the role of service quality, price and products on customer satisfaction and loyalty at BCA Insurance Solo.

The population in this study BCA Insurance customers in Solo. The number of samples used was 100 respondents with a purposive sampling technique. The analysis technique used is the validity test and reliability test, linearity test, regression analysis, path analysis, partial test $\mathrm{t}, \mathrm{F}$ test, coefficient of determination test and correlation analysis.

The results showed that: service quality, price and products had a positive and significant effect on customer satisfaction. Service quality, price, products and satisfaction have a positive and significant effect on customer loyalty. The path analysis results show that: The direct effect of service quality on customer loyalty is more effective through the direct path. The direct effect of price on customer loyalty is more effective through a direct path on price variables. The direct effect of the product on customer loyalty is more effective through direct channels on product variables. The results of the path analysis prove that the satisfaction variable is not a mediating variable. The total $\mathrm{R}^{2}$ test results of 0.913 can be interpreted as BCA Insurance Solo customer loyalty explained by the variable service quality, price, products and customer satisfaction by $91.3 \%$.

Keywords: Service Quality, Price, Products, Satisfaction, Customer Loyalty, BCA Insurance Solo

\section{PENDAHULUAN}

Perusahaan dalam menghadapi pesaingnya, harus mempunyai strategi dan ketegasan langkah sesuai dengan sifat dan bentuk pasar yang dihadapinya. Strategi pasar itu meliputi pelayanan yang memuaskan, harga yang lebih murah ditambah potongan harga apabila pembelian dalam jumlah banyak, kemasan yang menarik, tempat yang nyaman serta sistem yang mudah diakses sehingga akan mempengaruhi keputusan pelanggan untuk bertransaksi. Perusahaan dengan demikian diharapkan 
akan mampu mempengaruhi pembeli untuk bersedia membeli barang-barang yang ditawarkan oleh perusahaan.

Manajemen pemasaran perlu memahami keinginan dan sikap pelanggan terhadap produk jasa atau barang yang dihasilkan agar produk yang ditawarkan berhasil di pasar. Keinginan pelanggan atau sikap pelanggan muncul berdasarkan pandangannya terhadap produk dan proses belajar baik dari pengalaman ataupun informasi yang diperoleh dari orang lain. Keinginan dan sikap menyebabkan orang berperilaku tetap terhadap satu obyek yang sama atau berganti obyek.

Keadaan pasar yang semakin kompetitif, mendorong BCA Insurance Solo untuk meninjau kembali pendekatan strategi pemasaran yang digunakan agar kepuasan pelanggan atau nasabah dapat tercapai secara maksimal. Faktor pelayanan kepada nasabah oleh BCA Insurance Solo masih harus ditingkatkan, juga strategi harga berupa memberlakukan potongan harga untuk pembelian produk yang jumlah tertentu harus dilakukan. Produk yang ditawarkan oleh BCA Insurance Solo juga masih harus diintensifkan, diharapkan mampu menjaring nasabah potensial. Pengenalan produk dengan media produk yang menarik seperti menjadi sponsor kegiatan masyarakat maupun pemasangan iklan pada media elektronik juga perlu diupayakan.

Bagi perusahaan perbankan kepuasan nasabah merupakan faktor yang sangat penting dan menentukan keberhasilan suatu badan usaha karena nasabah adalah pengguna dari barang yang dihasilkannya. Nasabah yang merasa puas akan mendorong atau menciptakan loyalitas nasabah. Hasil penelitian yang dilakukan oleh Henri (2016), Susanti (2016) dan Yuliani (2016), menunjukkan bahwa kepuasan berpengaruh signifikan terhadap loyalitas. Walaupun hasil penelitian yang dilakukan oleh Krismanto (2015) menunjukkan bahwa kepuasan berpengaruh tidak signifikan terhadap loyalitas.

Kesenjangan teori hubungan antara kepuasan dengan loyalitas dan temuan hasil penelitian (teori gap) serta kesenjangan antara temuan hasil penelitian (riset gap) menjadi hal menarik untuk dikaji lebih mendalam. Hubungan dua variabel yaitu kepuasan dengan loyalitas nasabah, merupakan arah yang akan dikaji dalam penelitian ini.

Penerapan strategi pemasaran yang tepat bagi perbankan dapat mempengaruhi para calon nasabah untuk membuat suatu keputusan pembelian. Keputusan nasabah dalam mengambil keputusan pembelian dipengaruhi oleh berbagai faktor, terutama informasi tentang produk yang akan dibeli. Perusahaan untuk mengetahui sikap nasabah terhadap produknya, maka perlu mengadakan penelitian tentang faktor-faktor yang terdapat pada produk tersebut yang dapat mendorong terciptanya suatu motif pembelian. Penelitian atau survei perlu dilakukan perusahaan untuk menganalisis tanggapan nasabah terhadap kualitas pelayanan, harga dan produk atau jenis produk yang dihasilkan. Perusahaan dapat menilai faktor-faktor mana yang belum sesuai dengan keinginan dan kebutuhan nasabah. Berdasarkan hasil penelitian tersebut perusahaan dapat mengembangkan dan menyempurnakan produknya agar lebih memuaskan nasabah. Analisis terhadap sikap nasabah yang dilakukan perusahaan akan memberikan informasi yang berguna bagi pihak manajemen untuk menjalankan strategi pemasarannya.

Produk dapat dimaknai sebagai suatu sifat yang komplek baik dapat diraba maupun tidak dapat diraba, termasuk bungkus, warna, harga, prestise perusahaan dan pengecer, yang diterima oleh pembeli untuk memuaskan keinginan dan kebutuhannya. Produk harus diimbangi dengan adanya kualitas pelayanan yang terjamin bagi nasabah (Parasuraman et al,.2018)

Kualitas dan peningkatan pelayanan merupakan bagian yang penting dalam strategi pemasaran dan dapat meningkatkan loyalitas nasabah. Loyalitas merupakan intensitas dalam pembelian yang dilakukan oleh nasabah oleh karena beberapa hal yang ditawarkan pihak perbankan. Intensitas pembelian ini sangat tergantung bagaimana nasabah mengambil keputusan dalam melakukan pembelian. Dalam tahap evaluasi, para nasabah membentuk preferensi atas merek-merek yang ada di 
dalam kumpulan pilihan. Nasabah tersebut juga dapat membentuk niat untuk membeli merek yang paling disukai.

Nasabah sekarang membutuhkan sebuah alasan (meaning) yang lebih tinggi dari pada sekedar kelebihan fungsional dan emosional semata. Bagi perusahaan perbankan, dengan demikian tidak cukup jika hanya mencoba mengunci loyalitas pelanggan dengan menawarkan produk yang paling convenience, paling berkualitas, paling murah, paling unik atau bahkan paling experiential. Perusahaan sekarang dituntut untuk mengunci nasabah bukan hanya mind-nya, atau herat-nya, tetapi harus menunjang pada spirit nasabah. Jika hal ini berhasil, maka loyalitas yang terbentuk akan tahan lama karena bersumber dari keyakinan (belief).

Faktor lain yang dapat mempengaruhi loyalitas nasabah menurut Parasuraman et al,. (2018) adalah harga. Harga merupakan satu-satunya elemen marketing mix yang menghasilkan pendapatan. Perusahaan harus mempertimbangkan berbagai faktor dalam membuat kebijakan atas penetapan harga jual. Harga merupakan faktor utama yang mempengaruhi nasabah ketika membeli suatu produk perbankan. Nasabah akan lebih tertarik untuk membeli sebuah produk dan jasa dengan harga yang murah.

Produk adalah hal yang penting pada sebuah bank. Produk-produk yang dihasilkan bank harus sesuai dengan kebutuhan dan keinginan nasabahnya. Jika nasabah terpenuhinya kebutuhan, maka nasabah akan tetap memilih bank tersebut dan tidak pindah ke bank lainnya. Nasabah akan meyenangi produk yang menawarkan mutu dan kinerja yang baik serta keistimewaan yang mencolok. Produk yang ditawarkan oleh perbankan pada umumnya berupa produk tabungan, pinjaman, deposito, giro, kartu kredit dan e-banking lainnya. Jika produk yang ditawarkan sesuai dengan kebutuhan nasabah, maka nasabah akan puas dan pada akhirnya menjadi nasabah yang loyal. Hasil penelitian yang dilakukan oleh Susanti (2016) menunjukkan bahwa produk berpengaruh signifikan terhadap kepuasan dan loyalitas. Namun hasil penelitian yang dilakukan oleh Sasongko (2016), menunjukkan bahwa produk berpengaruh tidak signifikan terhadap kepuasan. Berdasarkan fenomena, landasan teori, serta teori gap dan riset gap tersebut, maka perlu diuji kembali secara empirik pengaruh produk terhadap kepuasan dan loyalitas.

Hasil penelitian yang dilakukan oleh Henri (2016) menunjukkan kepuasan nasabah berpengaruh positif dan signifikan terhadap loyalitas. Kepuasan nasabah merupakan faktor yang sangat penting dan menentukan keberhasilan suatu perusahaan karena nasabah adalah pengguna dari barang yang dihasilkan. Kepuasan nasabah diharapkan akan menciptakan loyalitas nasabah terhadap perusahaan. Menurut Susanti, (2016) bahwa loyalitas nasabah (customer loyalty) merupakan komitmen secara mendalam, dibentuk untuk membeli kembali atau penggunaan kembali barang atau jasa secara konsisten pada masa mendatang.

Berdasarkan latar belakang masalah tersebut di atas, maka penelitian ini akan dilakukan dengan mengambil judul "Peran Kualitas Pelayanan, Harga Dan Produk Terhadap Kepuasan Dan Loyalitas Nasabah Pada BCA Insurance Solo".

\section{METODE}

Variabel independen terdiri dari kualitas pelayanan, harga, dan produk, sedangkan variabel intervening adalah kepuasan nasabah dan variabel dependen adalah loyalitas nasabah.

Populasi dalam penelitian ini adalah nasabah di BCA Insurance Solo yang berjumlah 197 agen. Adapun sampel yang diambil dalam penelitian ini adalah sebesar 50\% dari populasi 197 yaitu sebesar 98,5 dibulatkan menjadi 100 nasabah. Teknik pengambilan sampel dengan purposive sampling berdasarkan dengan dengan kriteria nasabahatau agen minimal melakukan 2 transaksi ulang. 
Excellent : Jurnal Manajemen, Bisnis dan Pendidikan

Vol 7, No 1 (2020) ; p.83-91; https://e-journal.stie-aub.ac.id/index.php/excellent

Untuk dapat mengetahui persamaan regresi dapat dilakukan dengan membuat model persamaan menggunakan metode analisis regresi jalur sebagai berikut (Ghozali, 2018: 161).

Persamaan Regresi :

$Y_{1}=a+\beta_{1} X_{1}+\beta_{2} X_{2}+\beta_{3} X_{3}+\beta_{4} X_{4}+e_{1}$

$\mathrm{Y}_{2}=\mathrm{a}+\beta_{1} \mathrm{X}_{1}+\beta_{2} \mathrm{X}_{2}+\beta_{3} \mathrm{X}_{3}+\beta_{4} \mathrm{X}_{4}+\mathrm{e}_{2}$

\section{HASIL PENELITIAN}

Tabel IV.11

Hasil Analisis Jalur Persamaan 1

Coefficients $\mathbf{s}^{\mathrm{a}}$

\begin{tabular}{|ll|r|r|r|r|r|}
\hline \multirow{2}{*}{ Model } & \multicolumn{2}{|c|}{$\begin{array}{c}\text { Unstandardized } \\
\text { Coefficients }\end{array}$} & \multicolumn{2}{c|}{$\begin{array}{c}\text { Standardized } \\
\text { Coefficients }\end{array}$} & \multicolumn{1}{c|}{ t } & \multicolumn{1}{c|}{ Sig. } \\
\cline { 3 - 6 } & & \multicolumn{1}{|c|}{ B } & Std. Error & \multicolumn{1}{c|}{ Beta } &, 571 &, 569 \\
& (Constant) & 1,268 & 2,220 & &, 001 \\
& Kualitas Pelayanan &, 330 &, 092 &, 315 & 3,570 &, 000 \\
& Harga &, 317 &, 079 &, 351 & 4,030 &, 013 \\
\hline
\end{tabular}

a. Dependent Variable: Kepuas an

Tabel IV.12.

Hasil Regresi Persamaan 2

Coefficient $s^{a}$

\begin{tabular}{|c|c|c|c|c|c|c|}
\hline \multirow{2}{*}{\multicolumn{2}{|c|}{ Model }} & \multicolumn{2}{|c|}{$\begin{array}{c}\text { Unstandardized } \\
\text { Coefficients }\end{array}$} & \multirow{2}{*}{$\begin{array}{c}\text { Standardized } \\
\text { Coefficients } \\
\text { Beta }\end{array}$} & \multirow[b]{2}{*}{$t$} & \multirow[b]{2}{*}{ Sig. } \\
\hline & & $\mathrm{B}$ & Std. Error & & & \\
\hline \multirow[t]{5}{*}{1} & (Constant) & 8,631 & ,926 & & 9,325 &, 000 \\
\hline & Kualitas Pelayanan & ,133 & ,041 & 209 & 3,244 & ,002 \\
\hline & Harga & ,124 & ,035 & ,227 & 3,509 & ,001 \\
\hline & Produk & ,130 & ,048 & ,169 & 2,706 & ,008 \\
\hline & Kepuas an & ,269 & ,042 & ,443 & 6,324 & ,000 \\
\hline
\end{tabular}

a. Dependent Variable: Loyalitas Nasabah

Uji Serentak (F)

Tabel IV.17

Hasil Uji F

ANOV A

\begin{tabular}{|rl|r|r|r|r|r|}
\hline Model & & $\begin{array}{c}\text { Sum of } \\
\text { Squares }\end{array}$ & df & Mean Square & $\mathrm{F}$ & Sig. \\
\hline 1 & Regression & 259,112 & 4 & 64,778 & 93,627 &, $000^{\mathrm{a}}$ \\
& Residual & 65,728 & 95 &, 692 & & \\
& Total & 324,840 & 99 & & & \\
\hline
\end{tabular}

a. Predictors: (Constant), Kepuasan, Produk, Kualit as Pelay anan, Harga

b. Dependent Variable: Loyalitas Nasabah

\section{Koefisien Determinasi / Varian Total}

Nilai $\mathrm{R}^{2}$ total sebesar 0,913 dapat diartikan loyalitas nasabah BCA Insurance Solo dijelaskan oleh variabel kualitas pelayanan, harga, produk dan kepuasan nasabah sebesar 91,3\% dan sisanya 8,7\% dijelaskan variabel lain diluar model penelitian, misalnya reputasi perusahaan, lokasi. 
Excellent : Jurnal Manajemen, Bisnis dan Pendidikan

Vol 7, No 1 (2020) ; p.83-91; https://e-journal.stie-aub.ac.id/index.php/excellent

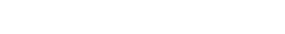

\section{Analisis Koefisien Korelasi}

Tabel IV. 22

\section{Hasil Analisis Koefisien Korelasi}

\begin{tabular}{|c|c|c|c|c|c|c|}
\hline \multicolumn{7}{|c|}{ Correlations } \\
\hline & & $\begin{array}{c}\text { Kualitas } \\
\text { Pelayanan }\end{array}$ & Harga & Produk & Kepuasan & $\begin{array}{l}\text { Loyalitas } \\
\text { Nasabah }\end{array}$ \\
\hline Kualitas Pelayanan & $\begin{array}{l}\text { Pearson Correlation } \\
\text { Sig. (2-tailed) } \\
\mathrm{N}\end{array}$ & $\begin{array}{r}1 \\
100\end{array}$ & $\begin{array}{l}, 565^{\star *} \\
, 000 \\
100\end{array}$ & $\begin{array}{c}578^{\star \star} \\
, 000 \\
100\end{array}$ & $\begin{array}{c}, 642^{\star \star} \\
, 000 \\
100\end{array}$ & $\begin{array}{l}, 719^{\star \star} \\
, 000 \\
100\end{array}$ \\
\hline Harga & $\begin{array}{l}\text { Pearson Correlation } \\
\text { Sig. (2-tailed) } \\
\mathrm{N}\end{array}$ & $\begin{array}{l}, 565^{* *} \\
, 000 \\
100\end{array}$ & $\begin{array}{r}1 \\
100 \\
\end{array}$ & $\begin{array}{l}, 565^{\star *} \\
, 000 \\
100\end{array}$ & $\begin{array}{l}, 654^{\star *} \\
, 000 \\
100\end{array}$ & $\begin{array}{l}1730^{\star \star} \\
, 000 \\
100\end{array}$ \\
\hline Produk & $\begin{array}{l}\text { Pearson Correlation } \\
\text { Sig. (2-tailed) } \\
\mathrm{N}\end{array}$ & $\begin{array}{l}, 578^{* *} \\
, 000 \\
100\end{array}$ & $\begin{array}{l}, 565^{\star \star} \\
, 000 \\
100\end{array}$ & $\begin{array}{r}1 \\
100 \\
\end{array}$ & $\begin{array}{l}, 603^{\star *} \\
, 000 \\
100\end{array}$ & $\begin{array}{l}, 685^{\star \star} \\
, 000 \\
100\end{array}$ \\
\hline Kepuasan & $\begin{array}{l}\text { Pearson Correlation } \\
\text { Sig. (2-tailed) } \\
\mathrm{N}\end{array}$ & $\begin{array}{l}, 642^{* *} \\
, 000 \\
100\end{array}$ & $\begin{array}{l}654^{\star \star} \\
000 \\
100\end{array}$ & $\begin{array}{l}, 603^{\star *} \\
, 000 \\
100\end{array}$ & $\begin{array}{r}1 \\
100 \\
\end{array}$ & $\begin{array}{l}, 827^{\star \star} \\
, 000 \\
100\end{array}$ \\
\hline Loyalitas Nasabah & $\begin{array}{l}\text { Pearson Correlation } \\
\text { Sig. (2-tailed) } \\
\mathrm{N}\end{array}$ & $\begin{array}{l}, 719^{\star \star} \\
, 000 \\
100\end{array}$ & $\begin{array}{l}, 730^{\star \star} \\
, 000 \\
100\end{array}$ & $\begin{array}{l}, 685^{\star \star} \\
, 000 \\
100\end{array}$ & $\begin{array}{l}, 827^{\star \star} \\
, 000 \\
100\end{array}$ & $\begin{array}{r}1 \\
100\end{array}$ \\
\hline
\end{tabular}

${ }^{\star *}$. Correlation is significant at the 0.01 level (2-tailed).

Model Hasil Analisis:

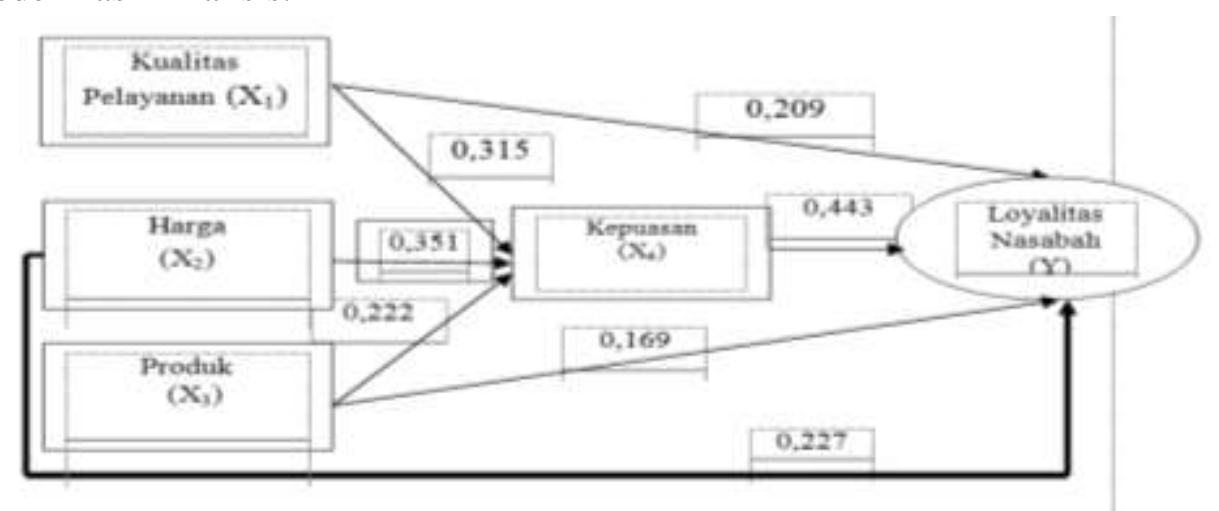

\section{PEMBAHASAN}

\section{Pengaruh Kualitas Pelayanan Terhadap Loyalitas Nasabah}

Pengaruh langsung kualitas pelayanan terhadap loyalitas nasabah lebih besar dibandingkan pengaruh tidak langsung, sehingga untuk meningkatkan loyalitas nasabah lebih efektif melalui jalur langsung. Hal ini mengidentifikasikan bahwa nasabah pada BCA Insurance Solo membutuhkan kualitas pelayanan yang baik sehingga nasabah akan tetap merasa loyal terhadap produk BCA Insurance Solo. Hasil penelitian ini mendukung hasil penelitian yang dilakukan oleh Sasongko (2016), Susanti (2016), Krismanto, (2015) menunjukkan bahwa kualitas pelayanan berpengaruh positif terhadap loyalitas nasabah.

Upaya yang dapat dilakukan seperti memperhatikan faktor-faktor yang dapat meningkatkan kualitas pelayanan antara lain melihat nilai indikator tertinggi pada uji validitas, yaitu dengan cara:

a. BCA Insurance Solo memberikan assurance atau jaminan pada setiap produk.

b. Pegawai BCA Insurance Solo memilki emphaty atau perhatian terhadap semua nasabah.

c. BCA Insurance Solo mempunyai pegawai yang kemampuannya sesuai dengan pekerjaan. 


\section{Pengaruh Harga Terhadap Loyalitas Nasabah}

Pengaruh langsung harga terhadap loyalitas nasabah lebih besar dibandingkan pengaruh tidak langsung, sehingga untuk meningkatkan loyalitas nasabah lebih efektif melalui jalur langsung. Hal ini mengidentifikasikan bahwa nasabah pada BCA Insurance Solo membutuhkan harga yang yang relatif terjangkau, sehingga dengan adanya harga yang terjangkau akan membuat nasabah akan tetap loyal terhadap produk BCA Insurance Solo. Hasil penelitian mendukung penelitian yang dilakukan oleh Sasongko (2016), Susanti (2016), Yuliani (2016) menunjukkan bahwa harga berpengaruh positif terhadap loyalitas nasabah.

Upaya yang dapat dilakukan untuk membuat harga stabil dan terjangkau seperti memperhatikan faktor-faktor yang dapat meningkatkan harga antara lain dengan melihat hasil uji validitas, yaitu dengan cara:

a. Harga yang diberikan kepada nasabah sesuai dengan kualitas.

b. Harga yang ditawarkan di BCA Insurance Solo bervariasi.

c. BCA Insurance Solo memberikan bonus berupa cash back kepada nasabah dengan syarat tertentu.

\section{Pengaruh Produk Terhadap Loyalitas Nasabah}

Pengaruh langsung produk terhadap loyalitas nasabah lebih besar dibandingkan pengaruh tidak langsung, sehingga untuk meningkatkan loyalitas nasabah lebih efektif melalui jalur langsung. Hal ini mengidentifikasikan bahwa nasabah pada BCA Insurance Solo membutuhkan produk yang lebih baik, lebih luas dan dapat dipahami oleh masyarakat luas, sehingga dengan adanya produk yang baik nasabah akan memahami kelebihan produk yang diberikan oleh BCA Insurance Solo, dengan hal tersebut maka loyalitas nasabah akan meningkat.

Hasil penelitian ini mendukung penelitian yang dilakukan penelitian oleh Sasongko (2016) dan Susanti (2016) menunjukkan bahwa produk berpengaruh positif terhadap loyalitas nasabah. Upaya yang dapat dilakukan seperti memperhatikan faktor-faktor yang dapat meningkatkan produk antara lain:

a. BCA Insurance Solo menjual produk yang berkualitas dibandingkan oleh bank lain.

b. BCA Insurance Solo memberikan jaminan mutu produk yang baik.

c. Produk yang dijual BCA Insurance Solo sangat bermanfaat bagi nasabah.

\section{Kesimpulan}

1. Hasil Uji t dapat disimpulkan bahwa:

a. Kualitas pelayanan berpengaruh positif dan signifikan terhadap kepuasan nasabah.

b. Harga berpengaruh positif dan signifikan $\mathrm{n}$ terhadap kepuasan nasabah.

c. Produk berpengaruh positif dan signifikan terhadap kepuasan nasabah.

d. Kualitas Pelayanan berpengaruh positif dan signifikan $n$ terhadap Loyalitas Nasabah

e. Harga berpengaruh positif dan signifikan terhadap loyalitas nasabah.

f. Produk berpengaruh positif dan signifikan terhadap loyalitas nasabah

g. Kepuasan nasabah berpengaruh positif dan signifikan terhadap Loyalitas Nasabah.

2. Hasil uji secara serempak (Uji F) pada persamaan kedua diketahui besarnya nilai $F=93,627$ dengan tingkat signifikansi $0,000<0,05$, sehingga dapat disimpulkan secara bersama-sama variabel bebas berpengaruh signifikan terhadap loyalitas nasabah.

3. Nilai $\mathrm{R}^{2}$ total sebesar 0,913 dapat diartikan loyalitas nasabah BCA Insurance Solo dijelaskan oleh variabel kualitas pelayanan, harga, produk dan kepuasan nasabah sebesar 91,3\% dan sisanya 8,7\% dijelaskan variabel lain diluar model penelitian, misalnya reputasi perusahaan, lokasi. 
4. Produk merupakan variabel paling dominan dalam meningkatkan loyalitas nasabah BCA Insurance Solo.

5. Hasil analisis jalur menunjukkan bahwa:

a. Pengaruh langsung kualitas pelayanan terhadap loyalitas nasabah lebih besar dibandingkan pengaruh tidak langsung, sehingga untuk meningkatkan loyalitas nasabah lebih efektif melalui jalur langsung.

b. Pengaruh langsung harga terhadap loyalitas nasabah lebih besar dibandingkan pengaruh tidak langsung, sehingga untuk meningkatkan loyalitas nasabah lebih efektif melalui jalur langsung pada variabel harga.

c. Pengaruh langsung produk terhadap loyalitas nasabah lebih besar dibandingkan pengaruh tidak langsung, sehingga untuk meningkatkan loyalitas nasabah lebih efektif melalui jalur langsung pada variabel produk.

6. Hasil analisis jalur membuktikan bahwa variabel kepuasan nasabah bukan merupakan variabel mediasi.

\section{Saran dan Rekomendasi}

1. BCA Insurance Solo dalam peningkatan loyalitas nasabah lebih meningkatkan harga yang lebih sesuai lagi dengan kebutuhan pasar, upaya yang dapat dilakukan antara lain:

a. Harga yang diberikan kepada nasabah sesuai dengan kualitas.

b. Harga yang ditawarkan di BCA Insurance Solo bervariasi.

c. BCA Insurance Solo memberikan bonus berupa cash back kepada nasaba gan syarat tertentu.

2. Penelitian mendatang dapat mengambil obyek lain yang lebih luas, agar hasil penelitian dapat digeneralisasikan.

\section{DAFTAR PUSTAKA}

Krismanto, A. 2015. Pengaruh kualitas pelayanan dan produk terhadap kepuasan konsumen Bank BPR. BKK Karanganyar”, Tesis STIE AUB Surakarta.

Anderson, E. and B. Weitz. 2018. "The Use of Pledges to Build and Sustain Commitment in Distribution Channel", Journal of Marketing research 29 (1), p.18-34.

Bolton, Ruth N and James H. 2013. " A Multi Stage Model of Customers Assessment of Service Quality and Value", Journal of Consumer Research, Januari, 1-9.

Bontis dan Booker. 2016. The mediating effect of irganizational reputation on customer loyalty and servive recommendation in perusahaaning industry" Journal Management Decion, Vol.45, No.9 p.1426-1445.

Brown, S. W. 2013. “A Multi Stage Model of Customers Assesment of Service Quality and Value”, Journal of Marketing, April, pp. 92-98.

Cronin J.Joseph Jr and Steven A. Taylor. 2017. “Measuring Service Quality : A reexamination and extension", Journal of Marketing Vol. 56 (July) p.55 - 68 
Davis, 2017. Kerangka Dasar: Sistem Informasi Manajemen, Bagian I Pengantar. Seri Manajemen No. 90-A. Cetakan Kedua Belas, Jakarta: PT. Pustaka Binawan Pressindo.

Djarwanto dan Subagyo, Pangestu. 2013. Statistik Induktif, Edisi: 4, Yogyakarta: BPFE.

Fornell, Claes; Johnson, Michael D ; Anderson, Eugene W ; Cha, Jaesun; Bryant, Barbara Everitt. 2016. "The American Customer Satisfaction Index : Nature, Purpose, and Findings". Journal of Marketing, 60 (10). (7 - 18).

Herbig, Paul, John Milewicz and Jim Golden. 2018. "A Model of Reputation Building and Destruction "Journal of Business Research. Vol.31, June 1994, No. 1 ; p.23-31.

Henri. 2016. Analisis Pengaruh Kualitas Pelayanan Terhadap Kepuasan Pasien Rawat Inap di Rumah Sakit PKU Muhammadiyah Yogyakarta. Jurnal Bisnis dan Manajemen Vol.2 No.3 UMS Surakarta

Istijanto. 2016. Riset Sumber Daya Manusia, Jakarta:PT. Gramedia Pustaka Utama

Juran, J.M. 2013. Quality Control Handbook, New York: Mc. Graw-Hill.

Liu, T dan dan Wu L.W. 2016. Customer retention and cross-buying in the organization industry: An Integration of service attributes, satisfaction and trust"', Journal of Financial Service Marketing, Vol.12 No.2 p.132-145.

Margaretha, 2014. 'Tinjauan Persepsi Manajemen Terhadap Struktur Modal Perusahaan Go Public'. Dalam Media Riset Bisnis dan Manajemen. Jakarta: Universitas Trisakti. No. 3. Hal. 98-115.

Marius. 2016. Consumer Behavion and Price, $5^{\text {th }}$ edition, McGraw Hill, New York, NY

Mandela. 2017. "Study Mengenai Loyalitas Konsumen Pada Rumah Makan Start Stick (Studi khusus di Jawa Tengah)", Jurnal Sains Pemasaran Indonesia, Vol III, No.3, Desember 2017. (289308).

Oliver, Richard L. 2017. "Satisfaction : A Behavioral Perspective on the Customer”, McGraw-Hill, New York, NY

Parasuraman, A.,A.Zeithmal, V.,\& L.Berry, L. 2015. A conceptual Model of Service Quality and Its Implications for Future Research, Journal of Marketing, Vol.49 (fall).

Prichard, mark P. 2015. "Analyzing the Commitment-Loyalty Link in Service Contexts", Journal of the Academy of Marketing Science 27 (3), p.333-348.

Sasongko. 2016. Analisis Pengaruh Kualitas Pelayanan, Harga Kompetitif, Kelengkapan Barang dan Produk Terhadap Loyalitas Pelanggan Di Swalayan Alfa Omega Baturetno, Wonogiri. Jurnal Manajemen Pemasaran Petra. Vol. 1, No. 2. Hal 2 dan 6.

Selnes, 2018. "An Examination of the effect of Product Performance on Brand Reputation, Satisfaction and Loyalty", European Journal of Marketing, 27 (9). (19-35). 
Setyo, Budiarto. 2013. "Pengaruh Kualitas Pelayanan terhadap Loyalitas Konsumen dan Citra perusahaan sebagai Variabel Intervening pada Apotek K-24 Jogjakarta” Pustaka Pelajar, Yogyakarta.

Singgih Priatmaji Sasongko. 2016. Analisis Pengaruh Kualitas Pelayanan, Harga Kompetitif, Kelengkapan Barang Dan Produk Terhadap Loyalitas konsumen Di Swalayan Alfa Omega Baturetno, Wonogiri. Jurnal Manajemen Vol.4 No.6 UNS Surakarta Pp.45-56

Solomon, Michael. 2016. Consumer Behavion, $3^{\text {th }}$ edition, McGraw Hill.

Solvang, B.K. 2017. Satisfaction, Loyalty, and Repurchase. Journal of Consumer Satisfaction Dissatisfaction and Comlplaining Behavior, Vol. 20. no.7. halaman 152-160

Sugiyono. 2013. Metodologi Penelitian Bisnis, Cetakan Keenam, CV. Alpabeta, Bandung.

Susanti, 2016, Analisis Pengaruh Kualitas pelayanan, Harga, Produk dan Kualitas produk Terhadap kepuasan dan Loyalitas konsumen (Studi Pada Waroeng Spesial Sambal Cabang Tembalang Semarang). Jurnal Sains Pemasaran Indonesia, Vol IV, No.3, Desember 2017. (123-245)

Swasta, Basu. 2013. Manajemen pemasaran Analisis Perilaku Konsumen. Yogyakarta: BPFE.

Swastha dan Irawan. 2013. Manajemen Pemasaran Modern. Yogyakarta: Liberty

Yuliani. 2016. Pengaruh Produk, Harga dan Pelayanan Terhadap Loyalitas konsumen di ABC Swalayan Probolinggo. Jurnal Sains Pemasaran Indonesia, Vol III, No.3, Desember 2016. (289-308)

Zeithaml, V. 2018. Consumer Perceptions of Price, "Quality, and Value : Means End Model and Synthesis of Evidence", Journal of Marketing, Vol 52, July, p.2-22

Zeithaml, Valerie; Berry, Leonard L,; and Parasuraman, A. 2018. "Sevqual: Multiple Item Scale for Measuring Consumer Perceptions of Service Quality", Journal of Retailing, Vol 64 No.1 Spring. 